\title{
Perfectionism and Moral Reasoning
}

\author{
Matteo Falomi
}

\section{(2) OpenEdition}

\section{Journals}

Electronic version

URL: http://journals.openedition.org/ejpap/903

DOI: 10.4000/ejpap.903

ISSN: 2036-4091

\section{Publisher}

Associazione Pragma

\section{Electronic reference}

Matteo Falomi, «Perfectionism and Moral Reasoning », European Journal of Pragmatism and American Philosophy [Online], II-2 | 2010, Online since 21 December 2010, connection on 10 December 2020. URL : http://journals.openedition.org/ejpap/903 ; DOI : https://doi.org/10.4000/ejpap.903

This text was automatically generated on 10 December 2020.

\section{(2) $\oplus \Theta \Theta$}

Author retains copyright and grants the European Journal of Pragmatism and American Philosophy right of first publication with the work simultaneously licensed under a Creative Commons AttributionNonCommercial-NoDerivatives 4.0 International License. 


\title{
Perfectionism and Moral Reasoning
}

\author{
Matteo Falomi
}

1 Since the late eighties, Stanley Cavell has begun presenting his reflections on ethics under the heading of Moral Perfectionism. ${ }^{1}$ Cavell's way of using the notion of perfectionism, though, considerably departs from the meaning the term has acquired in contemporary moral philosophy. In current debate, the word "perfectionism" usually names a certain kind of teleological theory, one that aims (as Rawls put it) at maximizing the good of "human excellence in art, science, and culture." In Cavell's understanding, instead, perfectionism should not be seen "as a competing moral theory [...] but as emphasizing a dimension of the moral life any theory of it may wish to accommodate." One might provisionally articulate the difference between Cavell's notion of perfectionism and the homonymous moral theory by saying that perfectionism, in Cavell's interpretation of it, focuses on a kind of moral difficulty that diverges from the ones usually considered in normative theories: while these theories try to answer questions about action, perfectionism concentrates on what Cavell variously describes as difficulties of "self-knowledge" of "becoming intelligible to oneself," ${ }^{5}$ of "being true to oneself," of "being lost to oneself" and "finding one's way," of "[becoming] the one I am." ${ }^{\prime 8}$ To put the contrast more sharply, one might say that while moral theories tries to answer questions of the form "What ought I to do?," perfectionism concerns itself with questions of the form "Who am I?"

2 Attention to this latter sort of difficulties requires, according to Cavell's account, modes of moral reasoning that deviate from the ones privileged in canonical moral theories: ${ }^{9}$ when one is confronted with difficulties of self-understanding, appeals to utilitarian calculations of consequences or Kantian generalizations of maxims may fail to make contact with one's actual concerns. ${ }^{10}$ Cavell, on the other hand, eschews any general characterization of the mode of thinking he associates with perfectionism: any version of perfectionism, in Cavell's view, will provide its own specific concepts and methods of selfunderstanding; the lineaments of perfectionist reasoning are therefore indicated by Cavell through an enumeration of examples of perfectionist texts, rather than fixed through a theoretical description. ${ }^{11}$ For this reason, it is hard to convey in a few lines the breadth and flexibility of Cavell's conception of perfectionism; in order to give at least a 
rough sense of what Cavell is prepared to count as an instance of perfectionist reasoning, I will list here a few examples that are relevant to Cavell's discussion:

1. Emerson's characterization of the reading of a "work of genius" as enabling us to "recognize our own rejected thoughts" coming back to us "with a certain alienated majesty." 12

2. Kierkegaard's strategies of indirect communication, as allowing us to realize that "we have lost the capacity, for subjectivity, for inwardness, and therewith the capacity for Christianity." ${ }^{13}$

3. Freud's methods of free association and dream interpretation, putting the patient in a position to recognize the elements of his inner life whose repression has led to psychological disorders. ${ }^{14}$

4. Rousseau's appeals to the idea of a social contract, as facilitating the acknowledgement that we have consented to "the specific inequalities, lacks of freedom and absence of fraternity" 15 that characterize our society as it stands.

5. Wittgenstein's methods of bringing words back to their everyday use, as enabling us to become aware that, in philosophy, we do not know what we mean by our words and that we are attracted by these nonsensical words because we want to refuse our human form of life. ${ }^{16}$

3 As it will be apparent even from this brief (and somewhat arbitrary) list, not only the methods of self-knowledge that Cavell deems relevant for perfectionism are extremely diverse, but each of these methods presupposes a different idea of self-knowledge: the kind of self-understanding delivered by Wittgenstein's grammatical investigations, for instance, will diverge from the one provided by Freudian therapies, and so on. Any attempt to characterize perfectionist self-knowledge in general is then bound to be partial or misleading. If one is nonetheless to indicate a pattern, one might say that all these authors respond, in different ways, to a peculiar kind of confusion about our conception of ourselves: we incur in such a confusion when we think that our present mode of life (or some feature of it) is really expressive of who we are, when in fact this is not the case. Emerson's reader, for instance, is imagined to be in a state of conformity, in which he believes that his present thoughts and tastes are his own, while he is actually imitating someone else; Kierkegaard's believer takes himself to be a Christian, and therefore lives under the illusion that "such thing as Christendom exists, that one can be a Christian simply by being born in a Christian state, by Christian parents, and by being given a Christian name and nomenclature"; ${ }^{17}$ Freud's patient is affected by systematic delusions over the real object of his desires; Rousseau's citizen hallucinates the real object of his consent; Wittgenstein's philosopher, who believes that in putting forward metaphysical propositions he is describing how things stand with an unprejudiced eye, turns out to be possessed by a refusal of the human.

4 All these methods of self-knowledge, in other words, may be said to exploit the idea of a mismatch between our present description of ourselves and our actual situation; they all respond to the sense that, as Nietzsche put the point in Schopenhauer as Educator, "all you are now doing, thinking, desiring, is not you yourself." ${ }^{18}$ The perfectionist quest for selfknowledge may be said to begin, in this perspective, with the acknowledgement that our present mode of life is not really ours; the different modes of reasoning that Cavell associates with the perfectionist tradition will then provide ways to come to terms with this acknowledgement. 
This admittedly crude sketch of perfectionism as a mode of moral reasoning is meant to prepare the ground for, and give some substance to, the question that I will consider in the rest of this paper. Even if one is willing to concede that the modes of reasoning indicated by Cavell can aptly be described as methods of self-knowledge, and even if (what is likely to be even more problematic) one is willing to see such methods as modes of reasoning, one might still wonder why Cavell insists to call these methods modes of moral reasoning. Moral reasoning, at least in a canonical understanding of it, is associated with the idea of an exchange of moral reasons for or against a certain course of action. What kind of connection can be drawn between this mode of discourse and the methods of self-understanding indicated by Cavell? It is not immediately evident, indeed, why one should count Freudian analysis or Wittgensteinian grammatical investigations as forms of moral reasoning. The sense that such methods are not relevant for moral thinking is registered, as Cavell himself notes, in the fact that most of the authors he associates with the perfectionist tradition are not normally included in the canon of moral philosophy (the claim holds also for the names mentioned in our brief inventory of perfectionist methods; other authors that Cavell includes in the perfectionist genre, and that are not generally seen as moral philosophers, are for instance Shakespeare, Schlegel, Thoreau, Ibsen, Marx, Heidegger, Beckett, etc.). ${ }^{19}$

6 The exclusion of perfectionism from moral philosophy might be motivated by the sense that the perfectionist questioning of the self is too private or too idiosyncratic to count as proper moral reasoning. But the perfectionist pursuit of self-knowledge may also invite more specific forms of resistance: one might think, for instance, that the concentration on the self that characterizes perfectionism is not simply irrelevant to morality, but rather actively opposed to its aspirations. In this perspective, as Cavell writes, perfectionism "may appear not to have arrived at the idea, or to disdain it, of other persons as counting in moral judgement with the same weight as oneself, hence to lack the concept of morality altogether." 20

7 A version of this concern emerges in Cavell's short discussion, in the preface to Conditions Handsome and Unhandsome, of the figure of the "scoundrel." With this term, Cavell wishes to designate those who "find their nature expressed in unshared and unshareable principles"21 (the term itself harks back to Rawls' response to an objection Sidgwick raised against Kant's moral philosophy: in Sidgwick's perspective, both the saint and the scoundrel are expressing their rational nature in their lives, if those lives are the outcome of their free choice). The possibility of such a figure, of course, may cast doubts on perfectionism's claim to the status of moral reasoning. The scoundrel, indeed, has a commitment to self-knowledge and self-realization, but this very commitment leads him to immorality: the scoundrel's concentration on his own self, in other words, elicits in him a disdain for the idea that others count as him in moral judgement. This suggests that a dedication to self-knowledge is at least independent from a commitment to morality, when it is not positively in conflict with it: and this, in turn, may make it hard to see how the methods of self-knowledge Cavell associates with perfectionism may count as instances of moral reasoning.

8 In this paper, I will provide an interpretation of Cavell's claim that perfectionism constitutes a mode of moral reasoning. As I will try to show, in Cavell's perspective, 
perfectionism not only contributes to moral thinking, but is also vital to it. While Cavell does not offer a sustained and explicit argument to back these claims, I believe that, by rearranging certain themes that recur in his writings on morality, one might reconstruct Cavell's line of reasoning on this point. In doing so I will focus, in particular, on Cavell's account of moral reasoning in Part 3 of The Claim of Reason: even if this account precedes the explicit introduction of the notion of perfectionism, some features of it may shed light on Cavell's understanding of the relation between moral reasoning and perfectionism (in adopting this approach, I will expand a parenthetical suggestion that Cavell enters in the Preface to Condition Handsome and Unhandsome, where he remarks that his writings on perfectionism are "however unpredictably, something of a continuation of the chapters in moral philosophy that constitutes Part 3 of The Claim of Reason"). ${ }^{22} \mathrm{My}$ aims in this paper will be mainly exegetical: in what follows I will not critically assess the conception of moral reasoning that Cavell puts forward, nor will I discuss the merits of his elaboration of perfectionism. What I hope to do is only to make available an underlying connection between these two regions of Cavell's thinking, and to clarify, thereby, the sense in which Cavell's work on perfectionism may constitute a contribution to moral philosophy.

One might follow many paths in Cavell's intricate discussion of moral reasoning in Part 3 of The Claim of Reason. For my present purposes, I will organize Cavell's remarks around the following question: What is the point of moral reasoning? Why we engage in the activity of asking and giving reasons, when discussing about a particular action, judgement or character?

10 As I will try to show, being clear about Cavell's conception of the point of moral reasoning may enable us to understand why Cavell is prepared to draw a connection between moral reasoning and self-knowledge.

11 Cavell's immediate interest in the question of the point of moral reasoning is generated by the sceptical threat that Charles Stevenson levels against the idea of moral rationality: Stevenson's account implies, indeed, that there is no such thing as moral reasoning, if by that we mean a form of discourse in which reasons are related normatively (then only psychologically) to the judgement they support; moral exchanges, in the emotivist perspective Stevenson defends, are nothing more than attempts to influence one's interlocutor attitude. ${ }^{23}$

Cavell, in replying to Stevenson, is led to examine a series of assumptions about moral reasoning - assumptions that shapes Stevenson's outlook and make his conclusions apparently irresistible..$^{24}$ Some of these assumptions bear on Stevenson's implied conception of the point of moral reasoning: Stevenson presupposes, among other things, that the aim of reasoning in general is to reach an agreement over a certain conclusion; moral exchanges, therefore, may be said to be rational only insofar as they are capable of producing convergence on a given judgement. The fact that moral arguments are characterized by persistent and irresolvable disagreements may then lead one to accept some version of Stevenson's picture: moral arguments only appear to be rational, but they are nothing more than a clash of conflicting attitudes. As Cavell observes: "some philosophers have taken the fact of moral disagreement to show the inherent 
irrationality of moral argument - show it essentially to be a matter of which side has the greater power, political, rhetorical, psychological, economic." 25

Cavell's strategy, in Part 3 of The Claim of Reason, consists in contesting this picture of moral rationality by questioning the assumptions that make the picture apparently compulsory. With respect to the assumption just mentioned, Cavell begins his rejoinder by noting that part of its force depends on the idea that science should be seen as the model of every rational enterprise. The connection between rationality and agreement, in fact, seems to be a characteristic feature of scientific discourse: scientific arguments are designed to bring, through the articulation of reasons every practitioner might recognize, to a conclusion every practitioner must accept. Cavell's attack on the assumption is here twofold. On the one hand Cavell observes that, even if the description just given characterizes accurately the kind of rationality that belongs to science, it is not clear why we should assume that the rationality of science is paradigmatic for rationality in general. On the other hand, and more importantly, Cavell argues that this account of rationality does not offer a faithful description of the kind of rationality science actually has. The point emerges, for instance, in the following passage:

But are we any longer quite so willing to take that Aristotelian who refused to look through Galileo's telescope in order to "see" the valleys of the moon, as a comic and irrational figure? If now a man refused to accept the evidence of telescopes as telling us of the nature of the moon, he would either be (we would regard him as) irrational or else incompetent in science. That man is no scientist, given the procedures or canons of science which now constitute that institution. Or again: what he says will not count for or against any proposition of science. Once these procedures and canons are established, then agreement is reached in familiar ways; but that simply means: agreement (or absence of disagreement) about what constitutes science, scientific procedure, and scientific evidence, is what permits particular disagreement to be resolved in certain ways. Being a scientist just is having a commitment to, and being competent at, these modes of resolution. ${ }^{26}$

Cavell is here distinguishing between two levels of agreement: the agreement that those who are committed to science may reach on a particular conclusion, and the agreement that these people have in being committed to science - namely, in finding the methods of science useful, interesting, valuable, and so on. Cavell, in this passage, proposes to connect the rationality of science with this second level of agreement: if someone, now that the methods of science are established, refused to follow them, he would count as irrational not because of his rejection of a particular conclusion, but because of his inability or unwillingness to see the importance of those methods. What makes this person irrational, in other words, is his refusal of the kind of interests and values that sustain our commitment to the procedures of science.

As Cavell notes, the dislocation of the connection between rationality and agreement in the case of science may help us to see the rationality of ethical discourse in a different light:

If what makes science rational is not the fact of agreement about particular propositions itself, or about the acknowledged modes of arriving at it, but the fact of a commitment to certain modes of argument whose very natures is to lead to such agreement, then morality may be rational on exactly the same ground, namely that we commit ourselves to certain modes of argument, but now ones which do not lead, in the same ways, and sometimes not at all, to agreement (about a conclusion). ${ }^{27}$

16 In this perspective, the fact of moral disagreement cannot be taken anymore as an evidence of the inherent irrationality of moral arguments. While it is true that there 
might be irresolvable moral disagreement on conclusions, morality (like science) is characterized by the fact that people agree in being committed to certain modes of argument - and the rationality of a given area of discourse is a function, in Cavell's view, of this second dimension of agreement. The difference between ethics and science, on this account, is not adequately expressed by the idea that the former is rational (because it is capable of producing agreement on conclusion) while the latter is not (because it is afflicted by interminable disagreements). What characterizes ethics is rather a peculiar economy of agreement and disagreement: in order to be morally rational, one must agree with others in being committed to certain modes of discussion; but these modes of discussions themselves are not necessarily aiming at producing a convergence on a given proposition. Here lies, in Cavell's view, the difference with science: in science, indeed, the modes of resolution to which we are committed lead an to agreement on a conclusion.

\section{米}

One might still want, at this point, to resist Cavell's description of rationality, or question it from a different point of view. It would be possible to object, for instance, that our commitment to the methods of science is not independent from its ability to produce convergence on a conclusion. The activity of giving and asking for reasons for a particular judgement, indeed, is valued just because it produces a convergence on a certain judgement: the fact that those who are involved in science can proceed from reasons everyone can recognize to conclusion everyone must accept ensures that the judgement thus reached is not influenced by imperfect information, arbitrary tastes, relations of powers, and so on. Our valuing this kind of result explains the point of our engaging in scientific reasoning: the importance of agreement on conclusions is the importance we attach to the achievement of a point of view that does not resent from any kind of idiosyncrasy or bias. On the other hand, it is not easy to see the purpose of engaging in a form of reasoning that does not lead to such an agreed conclusion: what could be the point of providing reasons in support of a judgement, if the exchange of reasons does not aim to show to our interlocutor that he must accept the judgement, independently from the interests, the desires, the values she may happen to have? In order to give substance to his hypothesis that the rationality of moral arguments does not necessarily involves convergence on a conclusion, Cavell must provide an alternative account of the point that such a mode of reasoning may have.

While Cavell does not explicitly address the issue in these terms, his answer to this concern might be reconstructed by looking at the comparison he draws between moral reasoning and ordinary epistemological reasoning (a study of this latter form of assessment, as Cavell notes, may illustrate our conception of rationality as clearly as reflection on scientific procedures). ${ }^{28}$ At a certain juncture of the comparison, Cavell contrasts the point of ordinary epistemological reasoning with the point of moral reasoning:

Questioning a claim to knowledge takes the form of asking "How do you know?" or "Why do you believe that?," and assessing the claim is, we could say, a matter of assessing whether your position (as Austin put it, your "credential and facts," your learning and perception) is adequate to the claim. Questioning a claim to moral rightness (whether of any action or any judgement) takes the form of asking "Why are you doing that?," "How can you do that?," "What are you doing?," "Have you really considered what you're saying?," "Do you know what this means?"; and 
assessing the claim is, as we might now say, to determine what your position is and to challenge the position itself, to question whether the position you take is adequate to the claim you have entered. The point of the assessment is not to determine whether it is adequate, where what will be adequate is itself given by the form of assessment itself; the point is to determine what position you are taking, that is to say, what position you are taking responsibility for - and whether it is one I can respect. What is at stake in such discussions is not, or not exactly, whether you know our world, but whether, or to what extent, we are to live in the same moral universe. What is at stake in such examples as we've so far noticed is not the validity of morality as a whole, but the nature or quality of our relationship to one another. ${ }^{29}$

19 In this passage, the difference between empirical and ethical reasoning is represented as a difference in their point or aim: while in the empirical case the point of the assessment is "to determine whether [your position] is adequate, where what will be adequate is itself given by the form of assessment itself," in the moral case "the point is to determine what position you are taking, that is to say, what position you are taking responsibility for - and whether it is one I can respect." How should one understand this contrast? The idea of "position," in this context, can roughly be taken to indicate the sort of normative responsibilities that are associated with a certain role: someone's position specifies, as Cavell writes a few pages later, "what he is doing and must do and ought to do." ${ }^{30}$ These responsibilities, in the case of ordinary factual reasoning, involve among other things a commitment to reply to all the grounds of doubts competently entered: if someone claims to know that there is a goldfinch in the garden, but then she is not able to answer the doubts raised by her interlocutors, she cannot insist that she knows that there is a goldfinch in the garden (if she does, she will be regarded as irrational or incompetent). ${ }^{31}$

21 Cavell writes in this sense that the normative commitments associated with this kind of epistemic position are established in advance by the form of the assessment itself: what you have to do, in order to occupy legitimately the relevant position, is already determined (you must, for instance, be able to reply satisfactorily to your interlocutors doubts); and the point of the exchange of reasons, in this context, is one of assessing whether you do in fact occupy the position to which your claim to know commits you.

This point marks, for Cavell, a crucial difference between empirical and moral reasoning. To use one of Cavell's own examples, if someone says that her brother must be buried, and her interlocutor replies that "he is an enemy of the state," the person can refuse to answer this ground for doubt without resulting irrational or incompetent: she might reply, in this situation, that she does not care that her brother is an enemy of the state, and insist in asserting that he must be buried..$^{32}$ It is important to note that this possibility does not have a parallel in the empirical case: if someone has defied competently your conviction that there is a goldfinch in the garden and you have not adequately answered the doubt, then you cannot insist that you know that there is a goldfinch in the garden (without being considered irrational).

23 This suggests that, in a moral argument, the relevant normative commitments are not established in advance by the form of the assessment itself. In the moral case, as Cavell notes, whether you must accept a certain reason as relevant to your claim is itself part of the moral conversation; while in the empirical case you cannot decide whether a reason adduced competently is relevant to the judgement at issue. In ethics, therefore, the point of the exchange of reasons cannot be to determine whether you actually comply with 
certain already defined requirements (since there are no such requirements). The point of moral reasoning is rather, as Cavell suggests, one of defining the kind of "cares and commitments" that we are prepared to recognize: the aim, in other words, is to define which normative commitments (which "position") you are acknowledging, not to assess whether the certain normative commitments known in advance are adequately met. To go back to Cavell's example, Antigone, by refusing to be shaken in her conviction by Creon's reasons, shows that she values family relations over the honour of the polis: in this sense, one might say that she is defining her cares and commitments to her interlocutor.

Cavell's discussion of the difference between factual and moral reasoning contains then a first indication on the point that the practice of giving and asking for reason might have in a moral context: such a practice aims to define your cares and commitments, the kind of things that "you do, you ought to do and you must do." The indication, though, should be regarded as incomplete and transitional, for Cavell clearly does not want to say that moral reasoning has the sole purpose of indicating one's cares and commitments to one's interlocutors. Such a formulation, indeed, might give the impression that moral reasoning, for Cavell, has an expressive function at best: moral arguments, in this perspective, would not involve the possibility of criticizing one's loyalties and attachments. But, as Cavell makes clear, in expressing the kind of reasons that qualify your position, you are also enabling your interlocutors to "to challenge the position itself, to question whether the position you take is adequate to the claim you have entered." In the course of moral conversations, your cares and commitments are not only declared, but also questioned.

The questioning of your position may happen in a variety of ways. The remark just quoted, for instance, suggests that one may criticize your position by assessing whether your professed concern for the honour of the polis expresses faithfully your position, or if your adherence to such values conceals others kinds of cares and commitments (say, a desire for power) of which you are unaware, or all too aware (in such a case, the position you are actually taking, involving for instance a commitment to power, would not be "adequate to the claim you have entered," say the claim that someone is an enemy of the state). The exchange of reasons might also show you how your professed position has implications that you have not considered, and that you might be unwilling to accept; or again, your interlocutor might question the appropriateness of the cares and commitments you are taking responsibility for, and urge you to change them.

It is in the course of such investigations that we might determine whether we can, as Cavell writes, "respect" the position of our interlocutors: a clarification of the respective moral position may enable us to see, for instance, that our interlocutor fully accepts the kind of responsibility that his professed position implies, or that such a position derives from a sincere commitment to the moral life, and not from an attempt to bypass or deny its requirements. In such cases, we might realize that we respect our interlocutor's position, even if we cannot share the particular moral judgement she entered.

In this sense, Cavell writes that in moral reasoning what is at stake is not "whether you know our world," but rather "the nature and the quality of our relationship with one another." The point of the exchange of reasons is not here, as in the epistemic case, one of attesting your competence over a certain fragment of reality, in order to get your 
interlocutors to converge on your judgement. The point of giving and asking for reasons is rather one of making yourself intelligible, in order to enable your interlocutors to decide whether, and how, they can continue their relationship with you in the face of your present disagreement. This account provides then an aspect of Cavell's description of the point of moral reasoning: the exchange of moral reasons may enable us to maintain relationships, when the divergences of our cares and commitments threaten their continuation. Cavell writes:

Morality [...] provides one possibility of settling conflict, a way of encompassing conflict which allows the continuance of personal relationships against the hard and apparently inevitable fact of misunderstanding, mutually incompatible wishes, commitments, loyalties, interests and needs, a way of mending relationships and maintaining the self in opposition to itself and to others [...] Morality [...] provides a door through which someone, alienated or in danger of alienation from another through his action, can return by the offering and the acceptance of explanation, excuses and justifications, or by the respect one human being will show another who sees and can accept the responsibility for a position which he himself would not adopt. ${ }^{33}$

The idea that moral reasoning involves a questioning of our position has, however, another implication - one that, for the purposes of the present discussion, it is particularly important to highlight. In the course of moral arguments, it is not only our interlocutor that gets to know better our cares and commitments: this is true for us as well. As we have already said, in exposing ourselves to moral reasoning, we might recognize a conflict among our cares and commitments of which we were unaware; or we might come to see that our cares and commitments have implications we are not prepared to accept; or again we might recognize that the description we give of our cares and commitments just masks our real attachments and needs, and so on. In all these cases, our understanding of our position is deepened and articulated by our participation in a moral exchange of reasons.

This suggests a further way of accounting for the point of moral reasoning, alongside the purpose of elaborating conflicts with others: when we engage in moral reasoning, we also aim to clarify the nature of our cares and commitments to ourselves; we aim, in short, at self-knowledge. As Stephen Mulhall has written, "more is at stake than the laudable and valuable attempt to maintain one's regard for and relationship with others when one engages in moral debate with someone; Cavell's claim is that participation in such debates is essential for self-understanding - for discovering and maintaining one's relationship with oneself." ${ }^{34}$ The point emerges very clearly, for instance, in the following passage from The Claim of Reason:

I have described moral arguments as ones whose direct point is to determine the positions we are assuming or are able or are willing to assume responsibility for; and this discussion is necessary because our responsibilities, the extension of our cares and commitments, and the implications of our conduct, are not obvious; because the self is not obvious to the self. To the extent that that responsibility is the subject of moral argument, what makes moral argument rational is not the assumption that there is in every situation one thing that ought to be done and this may be known, nor the assumption that we can always come to agreement about what ought to be done on the basis of rational methods. Its rationality lies in

European Journal of Pragmatism and American Philosophy, II-2 | 2010 
following the methods which lead to a knowledge of our position, of where we stand; in short, to a knowledge and definition of ourselves. ${ }^{35}$

knowledge might be irrational from the moral point of view, just like someone who is not
committed to the aims and procedures of science (someone that, for instance, does not see the point of gathering evidence on heavenly bodies by looking through a telescope) counts as irrational or incompetent in science. We might gain a better understanding of this point by considering a possible continuation of Cavell's fictional dialogue between Antigone and Creon. One can imagine, for instance, that Antigone may reply to Creon's protestation that Polyneices is an enemy of the state and therefore must not be buried by saying: "If you care so much about the honour of the state, then you won't want to make it responsible for such an inhuman deed." Here Antigone is questioning the nature of Creon's attachment to the polis, hence querying a fragment of his cares and commitments: the force of Antigone's moral reason, therefore, relies in this case on Creon's willingness to understand better his own cares and commitments. If Creon, on the other hand, is not committed to self-knowledge, then the sort of moral reason adduced by Antigone may not get a grip on him. In this sense Cavell remarks that one's moral rationality depends on one's commitment to methods of self-knowledge: someone who does not share an interest in self-understanding would not be, in this perspective, exposed to the force of moral reasons.

If Creon did not share that commitment he could, for instance, refuse to give any weight to Antigone's reason: he would not see, in this case, that the incoherence in his attachments indicated by Antigone requires him to redefine his position in some way (for instance, by retorting that his proposal is not inhuman, or by arguing that the honour of the state exactly requires to give merciless treatment to traitors, and so on). In this case, his attitude would be one of ignoring the relevance of Antigone's doubts. But this sort of stance is exactly what Cavell associates to the idea of being morally irrational, or incompetent:

What I cannot do, and yet maintain my position as morally competent, is to deny the relevance of your doubts [...], fail to see that they require a determination by me. 36 

elicited by a lack of interest in self-knowledge.

35 We are now in the position to sum up the results of our discussions of Part 3 of The Claim of Reason, and connect them to our original question: why is Cavell prepared to assert that perfectionism provides a form of moral reasoning? As we have seen, Cavell associates the point of moral reasoning with two different, but closely interrelated, kinds of aim: moral reasoning on the one hand aims to permit the continuation of human relationships when moral conflicts threaten their survival, and on the other wishes to provide ways to achieve a deeper understanding of one's position, of one's cares and commitments. Cavell also adds, relying on his discussion of the difference between moral and epistemic rationality, that the aspiration to self-knowledge is what makes moral reasoning rational: our commitment to self-knowledge, in this perspective, is what makes us exposed to the force of moral reasons in the first place. As these remarks already indicate, the idea of self-knowledge, which plays a crucial role both in moral reasoning and in perfectionism, may be pivotal for conjoining the two notions. Here is how Cavell spells out the connection in a couple of passage extracted from his writings on perfectionism:

\begin{abstract}
Any [moral] theory must, I suppose, regard the moral creature as one that demands and recognizes the intelligibility of others to himself or herself, and of himself or herself to others; so moral conduct can be said to be based on reasons, and philosophers will sometimes gloss this as the idea that moral conduct is subject to questions whose answers take the form of giving reasons. Moral perfectionism's contribution to thinking about the moral necessity of making oneself intelligible (one's actions, one's sufferings, one's position) is, I think it can be said, its emphasis before all on becoming intelligible to oneself, as if the threat to one's moral coherence comes most insistently from that quarter, from one's sense of obscurity to oneself, as if we are subject to demands we cannot formulate, leaving us unjustified, as if our lives condemn themselves. Perfectionism's emphasis on culture and cultivation is, to my mind, to be understood in connection with this search for intelligibility, or say search this search for direction in what seems a scene of moral chaos, the scene of a dark place in which one has lost one's way. ${ }^{37}$

[moral perfectionism] focuses [...] on the worth of a way of life, of my way of life, which has come to a crossroads demanding self-questioning, a pause or crisis in which I must assess what has been characterized as my being true to myself, something the romantics [...] articulated as the imperative to become the one I am. The claim of this field of concern to the status of morality is that the conversation required to assess my life [...] is one designed to make myself intelligible (to others, by way of making myself intelligible to myself). ${ }^{38}$
\end{abstract}

On the background of this set of remarks, it is possible to understand why Cavell claims that perfectionism counts as, or provides an interpretation of, moral reasoning. These passages hark back, implicitly but tangibly, to Cavell's discussion of moral reasoning in Part 3 of The Claim of Reason. Cavell describes here the point of moral reasoning in general as a matter of "making oneself intelligible." The description conveys in a single formula the two accounts of the aim of moral reasoning that can be extracted from The Claim of Reason: "making oneself intelligible" may mean in fact making oneself intelligible to others (thus managing to encompass otherwise irresolvable conflicts), but also making oneself intelligible to oneself (thus achieving a deeper understanding of one's own cares and commitments). 
37 Now, perfectionism counts as a form of moral reasoning because it is a further articulation of the "moral necessity of making oneself intelligible": as Cavell puts the point, "the claim of [perfectionism] to the status of morality is that the conversation required to assess my life... is one designed to make myself intelligible." While the kind of moral arguments examined in The Claim of Reason were directed at making the self intelligible both to others and to oneself, perfectionism puts its "emphasis before all on becoming intelligible to oneself." One might say, in this perspective, that perfectionism is isolating and giving prominence to a register that is already present in ordinary exchanges of moral reasons over a certain action: it is this focus on self-understanding that ensures perfectionism's relevance to the project of making oneself intelligible, hence to the practice of moral reasoning. Since self-knowledge counts as an inflection of the idea of making oneself intelligible, and perfectionism provides methods of self-knowledge, then perfectionism counts as a mode of moral reasoning.

It is important to stress that the line of reasoning we have just sketched accounts not only for perfectionism's relevance to moral reasoning, but also shows why, in Cavell's perspective, an acknowledgement of perfectionism is vital for moral reasoning. In order to see this, one must take into account that while perfectionism focuses primarily on selfknowledge, this dimension of moral thinking is crucial for moral arguments about actions as well: as we have already said, part of the point of such arguments is provided by the aspiration to self-knowledge, and it is a commitment to this very aspiration that makes us morally rational. If one excludes perfectionism from the sphere of moral reasoning, then one will be inclined to miss the dimension of self-knowledge that characterize, according to Cavell's account, also moral arguments about actions: this will result, accordingly, in a impoverishment or distortion of one's view of moral reasoning. One might be drawn, for instance, to overlook the fact that the articulation of moral reasons aims at the clarification of one's cares and commitments. This, in turn, may induce to think that the point of moral reasoning is not articulating one's position, but proving that one's position is adequate, and that therefore one's judgement must be accepted. In this perspective, the aims of moral reasoning are assimilated to those that characterize ordinary factual arguments. This tendency, elicited by an exclusion of the concern for self-knowledge from the area of moral thinking, is described by Cavell as a form of "moralization" of morality:

It is my impression that in established academic moral philosophy the question of moral standing, if it comes up at all, is grounded in one's conviction that one knows what is good or right for the other to do, so that the philosophical issue is essentially how to provide convincing, rational reasons for one's conviction; put otherwise, the point of the conversation is getting the other to agree, or to do, something. This is one feature of what I sometimes refer to as the risk of moralizing moral morality. The point accordingly assigned to moral conversation is that of rationally persuading the other to agree to, or to do, something that you are, independently of the conversation, persuaded that she ought to do. ${ }^{39}$

The question of moral standing, as Cavell explains elsewhere, is the question of the position from which you confront your interlocutor in a moral conversation: the very fact that you engage in a moral conversation with someone commits you to ask yourself what is the nature of your cares and commitments with respect to your interlocutor; as Cavell puts the point: "if you tell me 'neither a borrower nor a lender be', or 'To thine own self be true', you had better have some standing with me from which you confront my life, from which my life matters to you, and matters to me that it matters to you." ${ }^{40}$ Such 
questions, being questions of self-knowledge, are "pushed at the center of the stage in perfectionism." ${ }^{41}$

But if we exclude this sort of concern from our view of moral reasoning, then the very quality of our participation to moral reasoning will be significantly impaired. We might think, as Cavell suggests, that what licenses us to confront our interlocutors is just the fact the we are right "independently of the conversation," and that our only aim is to get our interlocutors to agree. One might see why such an attitude may count as moralistic: we are using morality, in this perspective, for aims that are not themselves examined from a moral point of view. If our attitude is marked by such a refusal of self-knowledge, the reasons that our interlocutors will put forward in the course of a moral conversation - reasons pointing at conflicts and opacities in our cares and commitments - will not probably get a grip on us. In this sense, the omission of the register of self-knowledge results in a failure in moral reasoning: since our willingness to understand ourselves is what makes us morally rational, an avoidance of self-knowledge will impoverish or obliterate our responsiveness to moral reasons. These remarks may accordingly illuminate why Cavell repeatedly asserts that perfectionism "emphasizes a dimension of moral life any theory of it may wish to accommodate," ${ }^{\prime 2}$ and that without such an account "moral reasoning runs the danger of moralism." 43

41 One might sum up the relation between perfectionism and moral arguments by saying that both these modes of discourse, in Cavell's view, have a common source: they both depend on, and are a manifestation of, one's dedication to self-knowledge. In this perspective, if someone is committed to moral reasoning, then she must also have an interest in perfectionist methods of self-understanding. This coordination of commitments illuminates why the perfectionist dimension is not only relevant to moral reasoning, but also necessary to it: the omission of perfectionism, indeed, may encourage a representation of moral arguments (and a practice of them) that prescinds from their relation with self-knowledge.

42 I would like to note, in concluding, that the connection I have just stated can also be read the other way round: if someone is committed to perfectionism, then she must also be committed to moral reasoning. This provides an indication on how one might approach, in Cavell's perspective, the issue of the scoundrel. The scoundrel, as we have seen, finds his true self expressed in unacceptable principles: one might say, in this sense, that the scoundrel is dedicated to the perfectionist quest for one's real self, but that on the other hand he is not committed to moral reasoning; reflection on such a character may accordingly invite to represent the sphere of morality as radically independent from the one of self-knowledge.

43 Cavell does not wish to deny the possibility of such a figure: what Cavell's arguments suggest is rather that we should question the genuineness of the scoundrel's commitment to self-knowledge. Such a commitment, as we have seen, implies a responsiveness to moral reasons: someone who is interested in expressing one's nature (and therefore in understanding oneself) must also be receptive to moral reasons; these reasons indicate, in fact, conflicts, omissions and opacities in one's cares and commitment. The scoundrel, in this perspective, appears as someone who lays claim to the expression of his real self, but who on the other hand is not willing to accept the kind of contribution to his selfunderstanding that may be provided (in the form of moral reasons) by his interlocutors in a moral argument. If this is the case, the scoundrel is criticisable not only from the point of view of morality, but also from the perspective of perfectionism. If morality derives 
from a commitment to intelligibility, then intelligibility to others and intelligibility to oneself are not separate tasks.

\section{BIBLIOGRAPHY}

CAVELl S., (1979), The Claim of Reason: Wittgenstein, Skepticism, Morality and Tragedy, Oxford, Clarendon Press.

CAVELL S., (1981), Pursuits of Happiness: The Hollywood Comedy of Remarriage, Cambridge, MA, Harvard University Press.

CAVELl S., (1984), Themes out of School: Effects and Causes, San Francisco, North Point Press.

CAVELL S., (1989), This New Yet Unapproachable America: Lectures after Emerson after Wittgenstein, Albuquerque, Living Batch Press.

CAVELl S., (1990), Conditions Handsome and Unhandsome: The Constitution of Emersonian Perfectionism, Chicago, University of Chicago Press.

CAVELL S., (2004), Cities of Words: Pedagogical Letters on a Register of a Moral Life, Cambridge, MA London, The Belknap Press of Harvard University Press.

CONANT J., (2001), “Nietzsche's Perfectionism: A Reading of Schopenhauer as Educator," in R. Schacht (ed.), Nietzsche's Postmoralism: Essays on Nietzsche's Prelude to Philosophy's Future, Cambridge, Cambridge University Press.

DAVIDSON A. I., (1994), "Ethics as Ascetics," in G. Gutting (ed.), The Cambridge Companion to Foucault, Cambridge, Cambridge University Press.

foucault M., (2005), The Hermeneutics of the Subject, New York, Palgrave MacMillan.

HURKA T., (1993), Perfectionism, Oxford, Oxford University Press.

MULHALl S., (1994), Stanley Cavell, Philosophy's Recounting of The Ordinary, Oxford, Oxford University Press.

NIETZSCHE F., (1983), Schopenhauer as Educator, in Untimely Mediations, Cambridge, Cambridge University Press.

RAWLS J., (1971), A Theory of Justice, Cambridge, Mass., The Belknap Press of Harvard University Press.

\section{NOTES}

1. Cavell's account of perfectionism is mainly developed in Cavell 1990 and 2004, though remarks on perfectionism are scattered all over his more recent output.

2. Rawls (1971: 286). An alternative definition of perfectionism identifies the good in the realization of human essence: in this perspective, the goods mentioned in Rawls' definition are 
valuable because they promote human flourishing; for this latter account of perfectionism, see for instance Hurka 1993.

3. Cavell (1990: xxxi).

4. Cavell $(2004: 13,17)$.

5. See for instance Cavell (1990: xxxi); see also Cavell (2004: 42).

6. Cavell (1990: 1)

7. Cavell (1990: 21); see also Cavell (1990: xxxii, 55).

8. Cavell (2004: 49).

9. See for instance Cavell $(2004: 32,42)$.

10. For a vivid exemplification of this point, see Cavell 's discussion of Ibsen's A Doll's House in Cavell (2004: 247-64); see also Cavell (1990: xxxi, 55).

11. This way of defining the notion of perfectionism harks back to Cavell's discussion of the notion of genre, but I cannot follow the details of Cavell's account here; on Cavell's discussion of genre, see for instance Cavell (1981: 23-34); on the application of this notion to Moral Perfectionism, see Cavell (1990: 4-8; 2004: 445-7).

12. See for instance Cavell (1990: 57-8). The quotations are extracted from Emerson's essay SelfReliance. Emerson is undoubtedly the central case for Cavell's treatment of perfectionism: on Cavell's reading of Emerson as a perfectionist author, see Cavell 1990.

13. Cavell (1984: 218). Cavell's writings on Kierkegaard precede the explicit introduction of the notion of moral perfectionism, but Cavell mentions Kierkegaard's Concluding Unscientific Postscript in his list of perfectionist works (Cavell 1990: 5).

14. On Freud's relation to perfectionism, Cavell (2004: 282-300).

15. Cavell (1979: 24). Cavell's discussion of Rousseau is mainly contained in a set of remarks about the social contract that Cavell presents in The Claim of Reason (1979: 22-8). While Cavell does not mention The Social Contract in his list of perfectionist texts (his choice falls rather on The Reveries of a Solitary Walker), many features of Cavell's reading of Rousseau's text clearly prefigure his elaboration of perfectionism.

16. The pertinence of Wittgenstein's Philosophical Investigations to perfectionism is repeatedly asserted by Cavell (1990: 2). The most sustained discussion of perfectionist themes in the Investigations is probably to be found in Cavell's "Declining Decline: Wittgenstein as a Philosopher of Culture," collected in Cavell 1989.

17. Cavell (1984: 217).

18. Nietzsche (1983: 127). Nietzsche's Schopenhauer as Educator counts as another central instance of moral perfectionism; see for instance Cavell's discussion of this text in Cities of Words (Cavell 2004: 208-26). Another reading of Nietzsche as a perfectionist, explicitly related with Cavell's, is offered by J. Conant 2001.

19. Cavell provides a list of perfectionist texts in Cavell (1990: 5). On the exclusion of perfectionist authors from the canon of moral philosophy, see Cavell (1990: 5-6; 2004: 5, 13). It is important to note that Cavell includes in the perfectionist genre also authors and texts whose relevance for moral philosophy is uncontroversial (such as, for instance, Aristotle's Nicomachean Ethics, Kant's Groundwork of the Metaphysics of Morals, Mill's On Liberty).

20. Compare with Foucault's discussion of modern distrust of care for the self: Foucault connects the negative association that the idea of caring for the self has for us with the sense that such outlook involves a form of egoistic concentration on the self (Foucault 2005: 12-3). Cavell, in Cities of Words, explicitly connect his work on perfectionism with Foucault's notion of caring for the self (Cavell 2004: 11). On the relation between Cavell's elaboration of perfectionism and Foucault's notion of the care for the self, see Davidson 1994.

21. Cavell (1990: xxxvi); see also Cavell (2004: 24-5).

22. Cavell (1990: xx).

23. For Cavell's discussion of Stevenson's Ethics and Language, see Cavell (1979: 247-91). 
24. See Cavell (1979: 260).

25. Cavell (2004: 25).

26. Cavell (1979: 261).

27. Cavell (1979: 261-2).

28. Cavell (1979: 264).

29. Cavell (1979: 268).

30. Cavell (1979: 325).

31. See Cavell (1979: 267).

32. See Cavell (1979: 267-8).

33. Cavell (1979: 269).

34. Mulhall (1994: 43).

35. Cavell (1979: 312).

36. Cavell (1979: 267).

37. Cavell (1990: xxxi-xxxii).

38. Cavell (2004: 49).

39. Cavell (2004: 235).

40. Cavell (2004: 50).

41. Cavell (2004: 50).

42. Cavell (1990: xxxi).

43. Cavell (2004: 316).

\section{ABSTRACTS}

Stanley Cavell presents Moral Perfectionism as a set of methods of self-knowledge, aiming at the clarification of one's understanding of oneself. Cavell also claims that Moral Perfectionism is a form or a dimension of moral reasoning. One might wonder, in this perspective, what relation can be drawn between perfectionist methods of self-knowledge and the practice of providing moral reasons for a certain action. In this paper, I propose to understand this connection on the background of Cavell's account of moral reasoning in Part 3 of The Claim of Reason. Cavell here contrasts the rationality of moral discourse with arguments that recur in epistemological and scientific contexts. While in these latter areas of investigation, the activity of giving and asking for reasons serves to establish one's position (i.e. one's authority to enter a given claim), in morality the aim is rather one of making one's position (that is, one's cares and commitments) intelligible, both to others and to oneself. I argue that this account may enable us to clarify to sense in which, in Cavell's perspective, perfectionism is both pertinent and vital for moral reasoning: since a dedication to self-knowledge is constitutive of moral discourse, the avoidance of such a dimension may impoverish and distort our conception of moral rationality. 